\title{
Cisplatin Regimen
}

National Cancer Institute

\section{Source}

National Cancer Institute. Cisplatin Regimen. NCI Thesaurus. Code C160011.

A chemotherapy regimen consisting of cisplatin that may be used in the treatment of head and neck, endometrial, vulvar, ovarian, fallopian tube, primary peritoneal, breast, and cervical cancers; and adult intracranial and spinal ependymomas (excluding subependymomas and myxopapillary ependymomas). 